\title{
O caráter específico do romance em Teoria do Romance de György Lukács e a liberdade em Schiller
}

\section{Bruno Moretti Falcão Mendes ${ }^{1}$}

Resumo: No presente artigo, tendo como centralidade a discussão acerca de $T d R$, de György Lukács, buscar-se-á apresentar Schiller como uma via de acesso e leitura aos aspectos fundamentais da autonomia e finalidade interna da obra ressaltados na estética de juventude de Lukács, apropriados aqui com o objetivo de convergir em torno de uma melhor formulação acerca da problemática do romance e o seu caráter qualitativamente único em sua relação com a época histórica, a virilidade madura do romance. Situando de modo histórico-filosófico a problemática das formas, tem-se a virilidade madura do romance enquanto totalidade fechada em si mesma, na configuração de sua forma projetando um mundo que não é mais adequado ao sujeito. $\mathrm{O}$ romance explicita algo sintomático diante do vivido, a liberdade de tornar-se autoconsciente da incompletude do mundo. Em Schiller, a criação poética como possibilidade de uma produção autêntica para a liberdade absoluta estaria delimitada pela subjetividade do gênio.

Palavras-chave: Lukács; romance; virilidade madura; Schiller; liberdade absoluta.

\begin{abstract}
At the present work, taking as centrality the discussion about The Theory of the Novel, by György Lukács, we'll search to present Schiller as a pathway for reading and access to the fundamental aspects of autonomy and internal finality of the work of art highlighted at Lukács' youth's aestetics, appropriated here targeting to converge around a better formulation about the novel's problematics and its qualitatively unique character regarding the historic period, the mature virility of the novel. Situating the problematic of the forms on an historical-philosofical mode, one achieves the mature virility of the novel as a self-enclosed totality, on the configuration of its form projecting a world which is no longer adequate to the subject. The novel explicits something symptomatic facing the lived, the freedom of becoming self-conscious of the incompleteness of the world. On Schiller, the poetic creation as possibility of an authentic production for absolute freedom would be delimited by the subjectivity of the genius.
\end{abstract}

Keywords: Lukács, novel, mature virility, Schiller, absolute freedom.

No presente artigo nossas preocupações giram em torno da Teoria do Romance, de György Lukács, atentando para o caráter específico que o autor salientara acerca do

1 É doutorando em Filosofia no Programa de Pós-Graduação em Filosofia da UNIFESP. Bolsista Capes. 
romance. O foco seria o elemento novo e único que o romance proporciona, a sua virilidade madura enquanto caráter específico em relação à época histórica, ou seja, a condição em que o romance torna-se a única possibilidade de configurar uma totalidade fechada em si, ainda que seja para desvelar a incompletude do mundo.

É justamente o tornar-se consciente dessa incompletude, como um autorreconhecimento dos limites subjetivos do sistema abstrato do romance, que mantém a fecundidade imanente da forma, no trato com a unidade orgânica do mundo. Tal unidade é propiciada pelo romance ao promover uma problematização objetiva da experiência subjetiva, ao tornar-se um espaço de liberdade e resistência diante do vivido e anunciar pela forma do romance que a totalidade extensiva dotada de sentido para experiência vivida não é mais possível, mas o romance marca essa cisão e a acompanha, desejando algo que foi perdido e tornando-se uma possibilidade de transcendência moderna diante das convenções formais que tornaram as aspirações da alma tão distantes da estrutura do mundo. Eis que a luta da forma romanesca consiste nessa permanente busca pela totalidade extensiva da vida, na máxima aproximação com a harmonia preestabelecida perdida, diante da atmosfera prosaica caracterizada por regularidades artificiais. Aqui há a liberdade em uma relação problemática com o mundo, que se exprime histórico-filosoficamente na dialética das formas. Não se trata, portanto, de uma liberdade absoluta, de uma liberdade como tarefa suprema a ser preparada pela criação mais autêntica do gênio artístico, como no ensaio "Sobre o Sublime",2, de Schiller.

A partir do foco na obra de Lukács, nossa leitura será a de promover um diálogo com a estética da época de Goethe, o classicismo de Weimar e, mais especificamente, Schiller, com a hipótese de que a noção de liberdade como tarefa suprema pela via artística, que promoveria uma unidade no âmbito da história e da natureza, aponta para um caminho estritamente subjetivo e distinto daquele traçado por Lukács. Nossa tese é a de que, se em algum momento Schiller permite que a produção para a liberdade escape das malhas determinadas da sensibilidade, como já aludimos acerca do ensaio Sobre o Sublime, tornando o espaço de criação para a liberdade um autêntico espaço de liberdade indeterminada e absoluta, teríamos a possibilidade de diálogo entre o seu pensamento e o de Lukács. Em Schiller, a autonomia da arte ainda estaria circunscrita à subjetividade do gênio, tal como Kant estabelece a universalidade subjetiva do Vladimir Vieira. Belo Horizonte: Autêntica, 2011. 
ajuizamento estético na Crítica do Juízo.

[...] um juízo estético é único em sua espécie e não fornece absolutamente conhecimento algum (tampouco um confuso) do objeto; este último ocorre somente por um juízo lógico; já aquele, ao contrário, refere a representação, pela qual um objeto é dado, simplesmente ao sujeito e não dá a perceber nenhuma qualidade do objeto, mas só a forma conforme a um fim de determinação das faculdades de representação que se ocupam com aquele. $\mathrm{O}$ juízo chama-se estético também precisamente porque o seu fundamento determinação não é nenhum conceito, e sim o sentimento (do sentido interno) daquela unanimidade no jogo das faculdades do ânimo, na medida em que ela pode ser somente sentida. ${ }^{3}$

Para Lukács, a autonomia e a finalidade interna da obra indicam que ela estabelece uma redução possível e harmônica de possibilidades. Isso significa que a realidade da obra não é a mesma realidade da efetividade vivida [Erlebniswirklichkeit], ou seja, há um claro distanciamento da forma artística em relação à imediaticidade da experiência sensível, embora não a transgrida. A centralidade na obra de arte significa dizer que os problemas fundamentais do ser podem ser pensados a partir de formas artísticas, que "fazer filosofia significa fazer filosofia da arte, ou seja, pensar o problema da forma artística em todas as suas dimensões"4.

Neste aspecto, convergindo em torno da problemática da modernidade, qual seja, a relação entre crítica e arte, já nos ensaios de A Alma e as Formas Lukács entende a Filosofia da Arte como a expressão autêntica da vida pelo conceito de forma, que em sua configuração contém valor intrínseco, como condição de verdade objetiva e das particularidades subjetivas. Não é por acaso que o jovem Lukács de A Alma e as Formas busca encontrar em cada ensaio uma forma adequada à relação entre vida e obra literária, suscitando uma unidade entre os ensaios, uma forma autônoma orientadora, dotada de sentido ético.

Estando em conexão permanente com a vida, a forma autônoma é a condição de expressão profunda de temas da vida que estão velados no plano da realidade vivida por necessitarem de uma "purificação" pela forma que projeta o ideal ante a imediaticidade sensível do real, mesmo que seja um processo de aproximação e distanciamento dificilmente atingido. Por conseguinte, o problema da estética do jovem Lukács parte da consideração da constituição interna da obra de arte e da autonomia de sua forma. A

3 Kant, Immanuel. Crítica da Faculdade do Juízo. Tradução de Valério Rodhen e Antônio Marques. São Paulo: Forense Universitário, 1983, § 15, p. 74.

4 SILVA, Arlenice Almeida da. A autonomia da arte em Lukács. Revista UFG, ano X, n. 4, jan./jun. 2008. 
forma autônoma permite, nas palavras do próprio Lukács, "uma nova ordenação conceitual da vida", o elevar a uma ordem, a uma harmonia homogênea aquele estado da realidade imediata que não se encontra nas condições de homogeneidade e é caracterizado pela multiplicidade fragmentária da vivência [Erlebnis].

A autonomia da forma diz respeito à possibilidade de promover uma elevação da vida conceitualmente, tendo a força necessária para circunscrever toda a riqueza da experiência vivida através do conceito, pois se trata não de uma redução da realidade imediata e sensível a um domínio transcendente da criação artística, mas, pelo contrário, de uma conceituação da Erlebnis por meio de um distanciamento e aproximação que a imagem dotada de significado pela forma mantém com a realidade vivida. A forma colocaria em debate filosoficamente, as questões vitais do ser, dotando de significado o tempo histórico, no primado da unidade coesa e harmônica - a totalidade na obra de arte -, e retirando algo de substancial e qualitativo da experiência vivida; tal procedimento só pode ser operado esteticamente.

É o próprio Lukács que nos conduz ao caminho das formas como uma condição de acesso a uma vida substancializada, a um segundo grau de vida como critério de orientação de ação nos termos de um valor normativo para essa ação. Denota-se do fundamento estético - as formas artísticas - uma fundação ética intrínseca nos textos de juventude de Lukács, que o acompanhará desde as primeiras obras, como As Almas e as Formas (1010-1911), até a gestação maior desse primeiro momento do autor, em Teoria do Romance (1916). Não é por acaso que no ensaio "Sobre a essência e a forma do ensaio: uma carta a Leo Popper”, presente na obra de 1010-1911, Lukács, ao distinguir a natureza específica do ensaio como exposição da forma artística, afirma que "na ciência, são os conteúdos que atuam sobre nós; na arte, são as formas; a ciência nos oferece fatos e suas conexões; a arte, almas e destinos" $\%$.

A arte, fechada em si mesma, afirma uma visão de mundo [Weltanschauung], pois inscreve o seu valor de eternidade como sentido de verdade, permitindo uma posição diante da vida. Desse modo, quando a forma substancializa a vida, elevando-a a caráter de valor e não circunscrito às necessidades da vida vivida, a cisão entre os dois mundos (o da imediaticidade sensível do cotidiano e o substancializado pela forma) torna latente o fato de que o mundo externo não poderia mais dar conta das pretensões

5 LUKÁCS, György. A Alma e as Formas. Tradução de Rainer Patriota. Belo Horizonte: Autêntica, 2015, p. 31 .

6 Ibid., p. 33. 
da alma.

Sobre as pretensões da alma, Lukács concentra em Anotações sobre Dostoiévski ${ }^{7}$ - escritos jamais levados ao término - o projeto de continuidade da tese conclusiva de Teoria do Romance ${ }^{8}$, a ideia de que a forma literária presente na obra de Dostoiévski já não seria mais a forma do romance, e sim uma superação às convenções formais e abstratas marcadas pelo alheamento em relação ao conteúdo concreto, abrindo a possibilidade de novas configurações fundadas em uma ética de ação, um "novo épos". É justamente em $T d R$, incialmente concebida para ser uma parte introdutória desse projeto mais amplo e sistemático, que se encontra a análise e o julgamento das obras literárias pela exposição das formas. $\mathrm{O}$ que o romance conserva de substancial diante de um mundo descompassado e sem saídas é o seu vínculo com a totalidade extensiva da vida, que se traduz na permanente busca pela unidade e sentido para a vida.

Uma vez que, para Lukács, o conceito liga-se à vida e a acompanha, denota-se um fundamento da especificidade do estético, o sentimento de nostalgia que leva os seres humanos a buscarem a unidade coesa e a ordem homogênea diante da multiplicidade dos elementos heterogêneos que os mesmos vivenciam, pois "desde que existe uma vida e os homens buscam compreender e ordenar a vida, existe essa dualidade em suas vivências [a imediata sensível e a substancializada pela forma]" ". A conceitualização pela forma no trato com as coisas da vida, o sentimento nostálgico por algo que já está rompido e a tentativa de dar conta das múltiplas particularidades da vivência pelo conceito podem ser expressos na formulação de Lukács no início de $T d R$, que diz que "a filosofia, tanto como forma de vida quanto como a determinante da forma e doadora de conteúdo de criação literária, é sempre um sintoma da cisão entre interior e exterior, um índice da diferença essencial entre o eu e o mundo $[\ldots]^{10}$.

Em suma, Lukács desenvolve esteticamente uma filosofia das formas como expressão do vivido, que em $T d R$ ganha um forte acento histórico, naquilo que é

7 Carlos Eduardo Machado nos oferece um bom exemplo a respeito da articulação entre o conceito de forma e a fundação ética, e formula a sua tese sobre a eticidade de um "novo épos" na forma literária da obra de Dostoiévski. Cf. MACHADO, Carlos Eduardo. Jordão. As formas e a vida: estética e ética no jovem Lukács (1910-1918). São Paulo: Editora UNESP, 2004.

8 A partir de agora, Teoria do Romance será denominada ao longo do texto como TdR.

9 LUKÁCS, György. op. cit., p. 36, acréscimo do autor.

10 LUKÁCS, György. A Teoria do Romance: um ensaio histórico-filosófico sobre as formas da grande épica. Tradução de José Marcos Mariani de Macedo. São Paulo: Duas Cidades; Editora 34, 2000, p. $25-$ 26. 
comumente chamado de uma dialética histórico-filosófica das formas, expondo uma experiência problemática da subjetividade, nos termos de uma tentativa de reconfiguração da unidade de uma totalidade extensiva da vida, mas que culmina no vazio e na opacidade de sentido. Nesse registro, o romance enquanto forma artística denota a sua especificidade exatamente por trazer de forma consciente e madura a incompletude e fragmentação do mundo, a problemática do ser reconhecida enquanto estrutura da forma como conteúdo do vivido, e não um mero apriorismo formal como na epopeia e no drama. Por essas condições o espaço de liberdade criado no romance, em $T d R$, é a liberdade no âmbito da efetividade, como relação dialética do indivíduo com o mundo.

Em Schiller, o tensionamento que a tendência estética promove diante da Wirklichkeit, através do jogo das faculdades, prepara uma liberdade ainda controlada, o ideal do belo como um jogo entre o caos do mundo sensível e fragmentário e a regularidade formal do entendimento. Nesse momento, presente em Educação Estética do Homem, o sollen Artístico ainda estaria condicionado pelas regras da sensibilidade. Porém, em Sobre o Sublime, Schiller reserva um espaço ilimitado para a liberdade a partir de princípios subjetivos do sujeito que não estão subsumidos pela natureza sensível do objeto, pois, como o próprio autor afirma, no sentimento do sublime "os impulsos sensíveis não possuem qualquer influência na legislação da razão" "11. Em nossas considerações, essa abertura para a liberdade indeterminada em Schiller é o que permite dialogar com outra noção de liberdade presente em $T d R$; uma noção de liberdade com referência ao conteúdo concreto e à sua efetividade, como relação dialética do indivíduo com o mundo.

\section{Lukács e a "virilidade madura" do romance em $T d R$}

Por qual motivo Lukács descobre o romance? Qual o caráter específico do romance que faz com que Lukács dedique toda uma obra a ele? Em primeiro lugar, é necessário situar de modo histórico-filosófico as formas artístico-literárias em $T d R$, na abordagem da forma romanesca, já que o autor precisava analisar casos concretos de historicidade e atemporalidade da obra de arte. Tal exemplo concreto Lukács encontra

11 SCHILLER, Friedrich. Sobre o Sublime, op. cit., p. 60. 
no romance moderno.

Será no terceiro capítulo da Filosofia da Arte de Heidelberg - intitulado Historicidade e atemporalidade das obras de arte [Geschichtlichkeit und Zeitlosigkeit des Kunstwerks] - que Lukács desenvolverá o caráter paradoxal e único de toda a obra de arte, pois ela é ao mesmo tempo temporal, com relação ao primado histórico, e atemporal ${ }^{12}$. Esse caráter manifesta-se a partir da eternidade de toda a obra de arte, pois como afirma Lukács no início do capítulo, "na eternidade das obras manifesta-se o caráter paradoxal dos valores estéticos fortemente. Eternidade que não pode representar outra coisa senão a validade atemporal, os valores, dos quais entram em cena na vivência condicionada pelo tempo"13. Por tal motivo, R. Rochlitz (1983) ${ }^{14}$ afirma que o capítulo em questão da obra de Lukács seria uma introdução à Teoria do Romance.

Uma obra é temporal porque tem uma gênese histórica, surge no tempo e se constitui no tempo. Contudo, ela também é atemporal no que diz respeito ao efeito de "eternidade" que a obra produz, ao tempo ideal em seu interior, intrínseco a ela e que não recolhe nada do núcleo temporal externo, como realização de valor que se torna universalmente válida. Esse duplo caráter, "que acentua de forma aguda a discrepância entre a temporalidade e a atemporalidade" ${ }^{15}$, está interligado de modo indissociável.

Portanto, toda obra instaura algo de qualitativamente único, fechado e incomparável em relação a obras anteriores, sendo a realização histórica pela forma (e não pelo conteúdo da matéria) a expressão da qualidade vivencial realizada, ou seja, ela figura pela forma tal qualidade vivencial específica do momento. Como qualidade concreta, a obra ganha uma forma, cravada, de um lado, na realidade utópica do possível, e, de outro, naquilo que ela tem de nostalgia por uma unidade e harmonia perdida. É a sua realidade como aquela do utopicamente possível que ascende para o caráter de eternidade de uma obra.

A qualidade única, específica e incomparável do romance moderno reside no fato do mesmo conter em determinado momento algo de significativo e irreversível da cisão de um tempo histórico: a solidão moderna figurada na luta e resistência do indivíduo isolado para com o mundo inacessível. No âmago da interioridade, do

12 Cf. LUKÁCS, György. Heidelberger Philosophie der Kunst. Darmstadt: Luchterland, 1974.

13 Ibid., pág. 153. Todas as traduções da respectiva obra são de nossa responsabilidade.

14 Cf. ROCHLITZ, Rainer. Le jeune Lukács. Théorie de la forme et philosophie de l'historie. Paris: Payot, 1983.

15 LUKÁCS, György. Heidelberger Philosophie der Kunst, op. cit., p. 153. 
autoconhecimento dá-se a luta e resistência contra um mundo alienado, da regularidade formal das leis da natureza, mas que "não se oferece como sentido para o sujeito em busca do objetivo nem como matéria imediatamente sensível para o sujeito que age"16.

O romance como sinal de um tempo histórico, como epopeia de uma era burguesa já havia sido exposto pela primeira vez por Hegel, em sua Estética. Ali, o romance é, como expressão de um mundo em que a leveza da unidade épica não se faria mais presente, e como "epopeia burguesa", uma luta e inconformismo contra o caráter prosaico e pragmático da "ordem segura e estável, a da sociedade burguesa e do Estado" ${ }^{17}$. Com a unidade e visibilidade orgânicas esfaceladas, o romance bem sucedido teria na figura do herói não mais a aventura cavalheiresca trivial em "busca de fins quiméricos, que só existem na imaginação subjetiva e não têm relação com o real" ${ }^{18}$, ou seja, o herói não busca mais fins particulares em circunstâncias isoladas que acabam explicitando o elemento cômico da situação, mas sim a lente do indivíduo que age com anseio do coração em realizar algo diante do caráter prosaico do pragmatismo do mundo, marcado pela fragmentação das contingências utilitárias das conexões da efetividade.

O herói do romance moderno, carregado de elemento épico, substitui o antigo herói das novelas de cavalaria, pois "trata-se agora de indivíduos que, com o seu amor, sua honra, suas ambições, suas aspirações por um mundo melhor, se opõem à ordem existente e à realidade prosaica que em todos os seus campos se ergue como um obstáculo"19. Tais indivíduos levam suas exigências subjetivas e anseios do coração ao conteúdo da experiência prática da vida, e essa luta do sujeito para com o mundo externo, que culmina em uma reconciliação, é o aprendizado necessário por que passa, por exemplo, Wilhelm Meister, marco do romance de formação [Bildungsroman].

Há, porém, nítidas distinções nas análises literárias entre a Estética de Hegel e a $T d R$ de Lukács. É possível marcar essa diferença a partir da análise de Dom Quixote, pois, se em Hegel a novela de cavalaria não representaria ainda a forma romanesca, em Lukács a novela quixotesca já representa uma luta interna contra o caráter prosaico do mundo, características que já associam a sua forma ao romance moderno. Na análise de 16 LUKÁCS, György. Teoria do Romance, op. cit., p. 62.

17 HEGEL, Georg W. F. Curso de Estética: o belo na arte. Tradução de Orlando Vitorino e Álvares Ribeiro. São Paulo: WMF Martins Fontes, 2009, p. 647.

18 Ibid., p. 645 .

19 Ibid., p. 647. 
Hegel, Dom Quixote ainda assemelha-se à forma medieval, em que a totalidade extensiva da vida ainda não penetra nos acontecimentos concretos como sentido geral. Aqui, a individualidade subjetiva do herói ainda está circunscrita em ações efêmeras e isoladas, sem condições de reivindicar a restituição de uma substancialidade ética perdida. Em suma, na análise de Hegel a novela quixotesca ainda não representa uma luta contra as imposições formais e convenções do mundo burguês e expõe a dualidade entre dois mundos: "um mundo ordenado pela razão e por uma lógica imanente, de um lado, e, de outro, uma alma isolada, com a pretensão de recriar esse mundo fatal à cavalaria, obedecendo aos princípios e regras da cavalaria que quer impor e acabando por se perder" 20 .

Diferentemente de Hegel, em Lukács Dom Quixote já representa uma luta do indivíduo contra o que o mundo moderno representa aos seus ideais e aspirações da alma. De acordo com a perspectiva de $T d R$, em Cervantes as objetivações do herói já dizem respeito aos aspectos globais da vivência, à totalidade extensiva da vida, e estamos diante de uma nítida articulação entre ética e estética, pois pela via éticosubjetiva dos seus heróis dá-se a possibilidade de resistência a um mundo que se fecha para eles em termos de sentido à imediaticidade da experiência sensível. A resistência interior do indivíduo isolado na configuração objetiva pela forma é a condição de incompletude de ação no mundo e limite da própria objetividade e, não obstante, marco e orientação de possibilidade de ação ética no mundo externo pela forma romanesca, ainda que problemática. O Dom Quixote de Lukács almeja a substancialidade ética perdida através da unidade na forma.

Se na perspectiva de $T d R$, contudo, Dom Quixote de Cervantes já apresenta as características da forma romanesca, a obra de Dante - aqui nos referimos à Divina Comédia -, também muito aludida por Lukács, é o registro de uma forma literária de transição, ou seja, embora a sua forma configuradora chegue próximo disso, ainda não é o romance. Em Dante não há luta e resistência contra a realidade mundana, pois, para ele, o homem com vínculos meramente mundanos seria um homem perdido em uma vida sem sentido.

O objetivo em estabelecer uma unidade substancial épica passa por uma transcendência divina, o universo divino e infinito na terra, como exigência para um sistema fechado e harmônico, o qual permite sentido para as finalidades humanas.

20 Ibid., p. 646. 
Embora se preserve ainda a unidade metafísica dos antigos, há em Dante uma preocupação com os aspectos fundamentais do ser, ao construir sistematicamente uma totalidade pela forma. Nas palavras de Lukács, o aspecto fecundo da totalidade extensiva da vida construída pelo círculo configurador transcendente traçado pelo mundo dantesco:

\begin{abstract}
A totalidade do mundo dantesco é a do sistema visível de conceitos. Justamente essa aderência sensível às coisas, essa substancialidade tanto dos próprios conceitos como de sua ordem hierárquica no sistema, é que permite à completude e à totalidade tornarem-se categorias estruturais constitutivas, e não regulativas; que faz com que a marcha através do todo, embora rica em emoções, seja uma viagem bem guiada e sem perigos, e não uma peregrinação tateante rumo ao objetivo; que possibilita a epopeia numa situação histórico-filosófica que já impele os problemas às raias do romance. ${ }^{21}$
\end{abstract}

A Divina Comédia não apresenta ainda a articulação entre forma e fundação ética, pois não há uma ética de ação diante de um mundo que escapa aos sentidos dos homens. O mundo dantesco é o espelhamento das condições histórico-filosóficas para a configuração da forma: um mundo em que o sentido ainda se dá de forma evidente, pois há a harmonia preestabelecida por Deus na finitude mundana da terra. $\mathrm{Na}$ forma do romance analisada por Lukács, por sua vez, a totalidade já não é mais dada de imediato em sua organicidade. O romance é imanente à vida, embora seja como convenção objetiva para além da própria experiência sensível do vivido, como interioridade abstrata do subjetivo. Mas o seu limite abstrato é o próprio limite fecundo da forma romanesca, o seu caráter de resistência. Falamos do alheamento em relação à concretude nesse mundo da convenção, e que, "a despeito de toda essa regularidade [formal, em leis necessárias], não se oferece como sentido para o sujeito em busca de objetivo nem como matéria imediatamente sensível para o sujeito que age"22.

A racionalização e o consequente desencantamento do mundo produziram um abismo entre o sujeito cognoscente e a sua ação afetiva no mundo; a estrutura do mundo tornou-se estranha ao homem e às suas necessidades sensíveis a ponto do acesso às questões mais amplas e fundamentais da vida dar-se apenas pela lente subjetiva, que não obtém nada mais do que uma realidade multifacetada. $\mathrm{O}$ todo extensivo pleno de sentido relativo à vivência já não é mais possível, mas continua a ser o objetivo do romance. E a

21 LUKÁCS, G. A Teoria do Romance, op. cit., p. 70-71.

22 Ibid., p. 62, acréscimo do autor. 
busca por esse objetivo tem no conceito de demonismo, segundo Lukács, um papel importante pelo direcionamento em relação ao todo, ao ir além de si mesmo e da simples individualidade subjetiva; em outros termos, a forma do romance tem no princípio unificador o seu objetivo, que por meio de uma ética-subjetiva apenas reforçará a tensão entre a interioridade e as convenções objetivas.

Dom Quixote, de Cervantes, exemplifica bem a forma de estreitamento da alma diante do mundo, o idealismo abstrato, em que o herói busca algo em suas aventuras. Porém, na tipologia construída por Lukács ao longo da $T d R$, o romance propriamente moderno configura-se no acentuado psicologismo do herói, ético-subjetivamente, em que a alma está dilatada em relação ao mundo. Trata-se do romance da desilusão. No presente texto, no entanto, não nos aprofundaremos na análise mais detida das tipologias.

Lukács afirma que a epopeia dá forma a uma totalidade extensiva da vida, fechada em si mesma, e o romance também busca pela forma composicional uma totalidade extensiva, orientada em torno do psicologismo interior do herói. Ambos, epopeia e romance, não diferem pela intenção configuradora do objeto, mas pelos elementos histórico-filosóficos específicos do romance que tornam latente a fissura de um momento específico da história. A totalidade abstrata do romance esclarece a incompletude de um mundo problemático e fragmentado, e não a oculta. Diz o autor:

\begin{abstract}
A estrutura do objeto - a busca é apenas a expressão, da perspectiva do sujeito, de que tanto a totalidade objetiva da vida quanto sua relação com os sujeitos nada têm em si de espontaneamente harmonioso - aponta para a intenção da configuração: todos os abismos e fissuras inerentes à situação histórica têm de ser incorporados à configuração e não podem nem devem ser encobertos por meios composicionais ${ }^{23}$.
\end{abstract}

O reconhecimento de que a forma do romance só pode preencher a vida de sentido pela via da interioridade indica a perda da imanência à vida empírica; aqui a discussão gira em torno do estranhamento dos homens em relação às estruturas conceituais produzidas. Como afirma Lukács, "as estruturas com que a alma se defronta no processo de sua humanização como cenário e substrato de sua atividade entre os homens" 24 indicam uma cisão operada no plano do ser, entre o ser e o dever ser,

23 Ibid., p. 60.

24 Ibid., p. 62. 
afirmada pelo desenraizamento das estruturas em relação ao sentido objetivo da vida e também em relação às necessidades sensíveis. Em suma, essa cisão diz respeito à substituição da realidade concreta pelo conceito de natureza, que culmina em uma expressão simbólica esvaziada de sentido. ${ }^{25}$

A primeira referência ao conceito de natureza diz respeito a um sistema de leis e regularidades formais, alheias ao sentido e exemplificadas na cisão entre a atividade do pensar e o conteúdo de ação. É na primeira natureza que os fragmentos do mundo produzidos subjetivamente não são submetidos a nenhuma orientação, sentido e unidade, como nos tempos da "cultura fechada". O que sobra, segundo Lukács, é uma substancialidade subjetiva depositária do sentido do mundo, que pode ocorrer livremente nas construções líricas.

Se o primeiro conceito de natureza diz respeito ao alheamento em relação ao sentido e à concretude sensível, a segunda natureza é a tentativa de reaproximação a tal concretude por meio de uma postura sentimental, como uma convenção sentimental normativa. Mas, como afirma Lukács, o reencontro sentimental com o conteúdo objetivo do mundo é a formulação de um "complexo de sentido petrificado que se tornou estranho" 26 . O estranhamento ocorre quando as aspirações da alma - o estado anímico das estruturas - não encontram mais solo seguro e adequado na realidade humana.

As duas formas de conceituação da natureza são o registro da "objetivação histórico-filosófica da alienação do homem em relação às suas estruturas" ${ }^{27}$. Quando as estruturas conceituais do conhecimento afirmadas como leis convertem-se, nas palavras de Lukács, "em lógica sublime e suprema de uma necessidade eterna, imutável e fora do alcance humano"28, todo o círculo traçado pelos homens da sua realidade vivida já não é mais adequado, "não é mais o lar paterno, mas um cárcere" 29 . Essa seria a ideia do romance, a ideia de um sujeito moderno que não encontra mais um objeto adequado a si

25 Sobre a questão do símbolo esvaziado, cf. SILVA, Arlenice Almeida da. O símbolo esvaziado: a teoria do romance do jovem György Lukács. Trans/Form/Ação, Marília, v. 29, n. 1, p. 79-94, 2006. Disponível em: $<$ http://www.scielo.br/scielo.php?script=sci_arttext\&pid=S0101$31732006000100006 \& \operatorname{lng}=\mathrm{en} \& n \mathrm{~mm}=\mathrm{iso}>$. Acesso em: 26 fev. 2016.

26 LUKÁCS. György. Teoria do Romance, op. cit., p. 64.

27 Ibid., p. 65.

28 Ibid., p. 65.

29 Ibid., p. 65. 
em um mundo prosaico, fragmentado e inacessível sensivelmente, não se adapta e é um desenraizado, "vive numa condição de 'sem-teto transcendental [transzendentalen Obdachlosigkeit]"30.

Dessa forma, o interesse de Lukács pelo romance consiste no fato de que, em determinado momento histórico, o romance tem a possibilidade de se tornar a forma literária que exprime de modo fecundo formas e condições do ser. Dito de outra forma, o romance é o espaço de liberdade, luta e resistência contra um mundo inacessível, que permite, no psicologismo interiorizado do herói épico, uma forma de resistência nos termos do autoconhecimento. O romance torna-se a única possibilidade de configurar uma totalidade fechada, ainda que abstratamente. Eis a virilidade madura do romance e o estatuto ético presente nas formas estéticas.

A forma do romance tem a especificidade que a diferencia de todas as outras formas literárias, que é a de apresentar na forma a fissura do mundo, possibilitando pela estrutura formal a consciência de que a dualidade entre a interioridade subjetiva e o mundo objetivo é irreconciliável, mas uma aproximação possível é a realidade anunciada pelo conceito movente de forma, no romance. Essa característica da forma do romance aponta para uma relação muito específica entre ética e estética, como elemento formalmente constitutivo na composição literária.

No romance, a intenção, a ética propriamente dita, penetra profundamente em direção ao todo. Por sua vez, a totalidade é igualmente condicionada pela estrutura formal e "realiza um equilíbrio dos elementos constitutivos" 31 . A intenção ética para o todo se torna visível e, mais do que isso, torna-se o conteúdo concreto estruturante na composição literária. A especificidade romanesca diz respeito à possibilidade de ação para a existência, propiciada por um conceito de forma não consumada, como um devir em processo. O equilíbrio a que Lukács se refere é a marca do ativismo característico da $T d R$, pois, ao negar a condição de existência "em repouso", abre-se a possibilidade de ação; o ser deixa de estar prefixado e passa a ser conceitualmente articulado entre o ser e o devir. O devir pela forma não é outra coisa senão a negação do fato consumado e a abertura para os estados de ação [a Tathandlung, na acepção fichteana].

É a abertura para os estados de ação que possibilita à subjetividade fazer a si mesma e superar-se em sua experiência. Há nessa questão uma ética-subjetiva que deve

30 MACHADO, Carlos Eduardo. As formas e a vida, op. cit., p. 55.

31 LUKÁCS, György. A Teoria do Romance, op. cit., p. 72. 
suportar a concretude do mundo e fazer-se objetiva com o autorreconhecimento da fissura existente no mundo. Aqui há o desvelamento de dois elementos: a abstração conceitual e os limites na intenção de acessar uma unidade de sentido para o mundo, ambos vinculados às condições de existência para o ser. Ao penetrar o conteúdo do mundo com as suas aspirações interiores, a subjetividade promove uma autossuperação, culminando em uma forma objetiva da ética-subjetiva.

A subjetividade que se põe como objetivo é a positividade da ironia formulada por Lukács. Esse fundamento ético que se desdobra na objetividade da experiência subjetiva, como elemento formal constituinte da forma romanesca, torna a ironia a maior aproximação possível da unidade. Porém, a unidade não reconcilia termos opostos, mas aproxima o condicionado dos vínculos orgânicos e o incondicionado da fragmentação do mundo. Não há mais no romance o apriorismo formal característico da epopeia, pois a forma romanesca está em permanente tensão com realidade vivida. $\mathrm{O}$ romance continua a ser, para Lukács, assim como em Hegel, a autêntica expressão da época burguesa marcada por fissuras e pelo isolamento do sujeito.

\section{Schiller e Lukács: aproximações e distanciamentos}

Se em Lukács, a liberdade na forma romanesca passa pela tensão com a realidade vivida, em Schiller, a questão da liberdade na filosofia da arte deve ser analisada levando-se em consideração os distintos momentos de formulação acerca da relação entre liberdade e criação artística. Em um primeiro momento, presente em Educação Estética do Homem, Schiller articula a ação moral fundamentada no incondicional da razão, a inclinação do dever, assimilada dos postulados da razão prática kantiana, com a criação artística, a expressão autenticamente livre do belo pela arte. Aqui, o preparo para a liberdade pela educação estética conjuga o incondicionado da razão moral com a necessidade sensível da natureza, pois, ainda amarrada aos parâmetros do sensível, não é possível definir a liberdade como indeterminada. No segundo momento, tendo como referência o ensaio Sobre o Sublime, Schiller tem a percepção de que o sentimento do sublime não está subsumido pelas forças da natureza, ou seja, há no homem um gênio que possibilita ir além de qualquer interferência do sensível nas leis da razão. O sublime permite então a expressão plena da liberdade indeterminada, portanto, a partir dessa segunda possibilidade para a liberdade, 
indeterminada e absoluta, buscamos um diálogo com a estética do jovem Lukács, e, mais especificamente, com $T d R$.

Lukács encontra no romance o caso concreto de historicidade e atemporalidade da obra de arte, sendo, mais do que isso, a possibilidade de encontrar na forma romanesca a afirmativa já expressa na Estética de Heidelberg em seu segundo capítulo A relação sujeito-objeto na estética [Die Subjekt-Objekt Beziehung in der Ästhetik] -, a de que a estética permite uma vivencialidade pura na relação do sujeito com o objeto artístico, ou, como afirma Lukács, permite a "unidade viva da plenitude conteudística de vivências que abarcam o humano em sua totalidade"32.

Lukács, diferentemente da tradição alemã presente na estética da época de Goethe, e aqui nos referimos, sobretudo, a Schiller, não entende a arte como o elemento que traz o homem pleno, inteiro, mas o elemento que é instaurado e tem a sua legitimidade no comportamento vivencial do sujeito; sujeito este que não está fadado aos grilhões da subjetividade, mas deve se constituir como ser-sujeito [subjekt-sein] em sua relação com o objeto, na objetividade da experiência subjetiva. A arte tem como finalidade uma redução harmônica de possibilidades para o sujeito, que conduz a uma totalidade fechada em si, a unidade (ainda que abstrata) propiciada em certo momento histórico.

Portanto, a forma romanesca diz respeito ao "homem inteiramente [Mensch ganz]" da "totalidade verdadeiramente plena no sujeito estético", não ao "homem inteiro [ganzen Menschen]"33. Para Schiller, o caminho da formação estética do homem poderia preparar a sua liberdade plena e absoluta, sendo o jogo das faculdades produzido pela especificidade do objeto estético uma possível instância de equilíbrio entre o nível do ser e do dever ser, como bem se constata em sua estética conciliadora, em Poesia Ingênua e Sentimental.

Em Poesia Ingênua e Sentimental, Schiller estabelece uma relação entre o objeto ingênuo, ligado ao mundo da natureza e ao antigo, e o objeto sentimental, ligado à cultura ocidental na modernidade. Porém, não se trata de uma oposição fixa entre as duas esferas, mas, sim, de uma interdependência necessária, tendo em vista que o objeto ingênuo seria marcado pela harmonia e clareza das regras necessárias, e a convenção sentimental marcada pela artificialidade do prosaico e abstrato, pelo distanciamento em

32 LUKÁCS, György. A relação sujeito-objeto na estética. Tradução de Rainer Patriota. Artefilosofia, Ouro Preto, n. 14, p. 10, jul. 2013.

33 Ibid., p. 10. 
relação à adequação substancial entre a subjetividade e a experiência sensível (referimonos aqui à adequação entre o ser e o dever ser), assim como Lukács sugere em $T d R$.

Mas o objeto ingênuo e, especialmente, o poeta ingênuo, da substancialidade da vida, ficaram no passado e só podem ser retomados como ideal; ademais, a submissão irrestrita à natureza não permitiria a vontade livre do homem, e as conquistas culturais elevam a liberdade humana, ainda que culminem na artificialidade e no caráter fragmentário da experiência objetiva do mundo moderno. Só podemos exprimir a liberdade pelo ideal da razão, pelo processo de formação pela cultura [Bildung] e pelo claro afastamento da condição natural, mas que nesse registro ainda não significa uma expressão da liberdade que se eleva acima do poder da natureza. É o próprio autor que situa o ideal estético pela razão ao definir a relação de afastamento e interdependência com os objetos ingênuos, pois "fomos natureza com eles, e nossa cultura deve reconduzir à natureza pelo caminho da razão e da liberdade" ${ }^{\prime 4}$.

Em Schiller está presente a tendência romântica de atribuir à dimensão subjetiva do gênio artístico a possibilidade de educar o homem inteiro, que será objeto de crítica por parte de Lukács no início do século XX. Dessa forma, a tendência estética schilleriana como um caminho de preparação para a liberdade e indeterminação, para a liberdade absoluta, estaria circunscrita à subjetividade, ainda que a arte fosse entendida como uma possibilidade de união entre a história e a natureza, ou, no caso da obra Sobre o Sublime, como algo que está em nós para além da estrita natureza racional, mas como "natureza sensível-racional [...] que pode ser despertada por certos objetos sensíveis e cultivados por meio de uma depuração dos seus sentimentos até alcançar essa impulsão idealista de ânimo" 35 .

A arte teria como função recompor a imagem do mundo como totalidade perdida e desenvolver o novo caráter humano, não com a eliminação das dimensões empírica e da razão, mas promovendo uma mediação entre estas com o móbil artístico e lúdico, o impulsivo que reconstrói a unidade do espírito humano pelo caminho da formação. Portanto, a união entre a atividade moral e o juízo estético envolve, por um lado, a postulação dos princípios da legislação moral e, por outro, a necessidade dos sentimentos da sensibilidade. É o que Schiller chama de jogo entre o impulso sensível e o impulso formal, que significa a possibilidade de estabelecer a unidade entre o homem

34 SCHILlER, F. Poesia Ingênua e sentimental. Tradução de Márcio Suzuki. São Paulo: Iluminuras, 1995 , p. 44.

35 Id. Do Sublime ao Trágico, op. cit., p. 57-58. 
sensível e o homem moral.

A esta altura Schiller tem consciência da impossibilidade de estabelecer um conceito empírico da beleza, fundado na experiência do sujeito. A experiência, sempre contingente, não dá conta da pretensão à universalidade presente no Ideal do Belo. Assim, em suas Cartas a Körner, Schiller anuncia o aspecto conflituoso que envolve a tentativa de abarcar a forma de representação do belo e a necessidade de uma dedução objetiva para o juízo estético. Diz ele:

[...] estabelecemos um conceito empírico de beleza, o qual todavia não existe. Tínhamos necessariamente de encontrar todas as nossas representações do belo em conflito com a experiência, porque a experiência não expõe absolutamente a Ideia do belo, ou antes, porque aquilo que se sente comumente como belo não é absolutamente o belo. $\mathrm{O}$ belo não é um conceito de experiência, mas antes um imperativo. Decerto, ele é objetivo, mas apenas como uma tarefa necessária para a natureza racional e sensível; na experiência real, porém, ela permanece comumente inacabada, e por mais belo que um objeto seja, o entendimento antecipador o torna um objeto meramente agradável. É algo inteiramente subjetivo se sentimos o belo como belo, mas deveria ser objetivo ${ }^{36}$.

Para Schiller, a unificação artística sob o prisma cultural dá-se sob o modelo moral, o imperativo categórico kantiano, que permite a ascensão à universalidade. Porém, partir do modelo moral poderia significar uma redução unilateral e rígida às regras do imperativo. Como diz Schiller, "a razão pede unidade, mas a natureza pede multiplicidade, e o homem é solicitado por ambas as legislações" ${ }^{37}$.

A formação de um novo caráter necessário à humanização plena exige a conjugação da objetividade genérica do dever ser com a subjetividade contingente do ser, pois a formação de um sujeito unitário envolve a possibilidade de realização da ideia do todo, enquanto ideal artístico. Na Carta IV de sua Educação Estética do Homem, Schiller fala das condições políticas em que o Estado poderia reintegrar a unidade da forma racional com o preenchimento enérgico da natureza sensível que grita por multiplicidade. No limite, o escopo ainda gira em torno do modelo moral para a constituição de uma comunidade ética e a matriz é a política.

36 BOLTEN, Jürgen. Schiller Briefe über die ästhetische Erziehung. Frankfurt/Main: Suhrkamp, 1984, 109. A tradução da respectiva obra é do Prof. Dr. Márcio Suzuki.

37 SCHILLER, F. Sobre a educação estética do homem. Tradução de Roberto Schwarz e Márcio Suzuki. São Paulo: Iluminuras, 2002, p. 28. 
Quando, portanto, a razão transporta para a sociedade física sua unidade moral, ela não deve ferir a multiplicidade da natureza. Quando a natureza procura afirmar sua multiplicidade no edifício moral da sociedade, isso não deve acarretar ruptura alguma à unidade moral; a força vitoriosa repousa a igual distância da uniformidade e da confusão. É preciso, portanto, encontrar a totalidade de caráter no povo, caso este deva ser capaz e digno de trocar o Estado da privação pelo Estado da liberdade ${ }^{38}$.

Entretanto, no decorrer das Cartas somos conduzidos por Schiller a uma mudança substancial na matriz de suas proposições, quando o autor opera um deslocamento do enfoque político para outro estritamente estético. Como esperar que o Estado leve adiante o projeto de realização da razão na ideia se o mesmo gerou o enrijecimento espiritual e a fragmentação do sujeito? Para Schiller, o Estado é que deveria ser o resultado histórico dessa ideia do todo.

É interessante apontar aqui que a formação de um novo caráter humano não poderia ser fruto dos meios que deram condições à fragmentação do sujeito. $\mathrm{O}$ reestabelecimento da totalidade do homem só poderia realizar-se por meio de uma forma que não estivesse circunscrita aos móbiles tradicionalmente opostos: o racional e o sensível. A arte seria o passo adiante no projeto de formação do espírito como unificação cultural no contexto da Aufklärung. A legislação moral promove a unidade e a forma necessária, mas Schiller não sucumbe a um unilateral rigorismo ético. O jogo entre os impulsos assume um papel fundamental para Schiller, que o faculta a contrapor a forma artística dos antigos com a forma artística da modernidade, e nos permite uma inflexão à Lukács ${ }^{39}$.

Em uma passagem famosa de suas cartas para a Educação Estética do Homem [Carta XV], afirma que "o homem só joga quando é homem no sentido pleno da palavra, e somente é homem pleno quando joga" ${ }^{40}$. Em outras linhas, o autor afirma o ponto matricial da arte a partir do impulso lúdico, já que, por ser o ideal artístico o

38 Ibid., p. 29-30.

39 Seguindo a tendência de se articular a oposição entre o pensamento sobre os antigos e os modernos, marco característico da Teoria Estética presente no Classicismo de Weimar, Schiller irá contrapor o mundo integrado e harmônico dos gregos com o dilaceramento da modernidade, bem como Lukács em Teoria do Romance. Diz Schiller: "Numa observação mais atenta do caráter do tempo, entretanto, admirar-nos-emos do contraste que existe entre a forma atual da humanidade e a passada, especialmente a grega. A glória da formação e do refinamento, que fazemos valer, com direito, contra qualquer outra mera natureza, não nos pode servir contra a natureza grega, que desposou todos os encantos da arte e toda a dignidade da sabedoria sem tornar-se, como a nossa, vítima dos mesmos" (2000, p. 35).

40 Ibid., p. 80. 
pondo nodal da Bildung integral, tal ideal poderia articular a educação da razão, sob as malhas do entendimento formal, e a educação dos sentidos.

Ao conferir a autonomia da arte, Schiller estabelece a possibilidade de uma educação plena para a liberdade a partir da experiência estética, e como o jogo poderia reintegrar a unidade do espírito. A arte tem as condições de exprimir a liberdade política, sendo que o homem pode fazer a si livre pela experiência das belas artes. A Bildung estética conciliaria as regras da sensibilidade na efetividade necessária com a universalidade dos postulados moralmente possíveis. Para Lukács, conforme a $T d R$, não há conciliação pela forma artístico-literária do romance, mas o desvelamento da fissura e a tentativa de aproximação possível da unidade pela estrutura formal.

Há, contudo, um segundo momento distinto no significado da relação entre liberdade e criação artística em Schiller. Se, no sentimento do belo, há uma relação de harmonia entre razão e sensibilidade, no sentimento do sublime as regras do sensível já não interferem nas leis da razão. É no segundo gênio que a liberdade se expressa para além das forças da natureza, e, o mais importante, "o sublime cria para nós, portanto, uma saída do mundo sensível"41. Aqui, a liberdade é indeterminada. No contraponto a essa noção, em Lukács, para ser autônoma, a arte não deve estar delimitada pela subjetividade do gênio, pois a perfeição harmônica, a possiblidade de uma totalidade fechada em si mesma, ainda que problemática e abstrata, decorre da relação com a vivência e não de uma disposição de gênio como condição para uma substancialização do sentimento do mundo.

\section{Referências Bibliográficas}

BOLTEN, Jürgen. Schiller Briefe über die ästhetische Erziehung. Frankfurt/Main: Suhrkamp, 1984.

HEGEL, Georg W. F. Curso de Estética: o belo na arte. Tradução de Orlando Vitorino e Álvares Ribeiro. São Paulo: Editora WMF Martins Fontes, 2009.

KANT, Immanuel. Crítica da Faculdade do Juizo. Tradução de Valério Rohden e Antônio Marques. São Paulo: Forense Universitária, 1983.

LUKÁCS, György. A Alma e as Formas. Tradução de Rainer Patriota. Belo Horizonte: Autêntica, 2015. . A teoria do romance: um ensaio histórico-filosófico sobre as formas da grande

41 SCHILLER, Friedrich. Sobre o Sublime, op. cit., p. 63. 
épica. Tradução de José Marcos Mariani de Macedo. São Paulo: Duas Cidades; Editora 34, 2000.

. A relação sujeito-objeto na estética. Tradução de Rainer Patriota. Artefilosofia, Ouro Preto, n. 14, jul. 2013.

. Die Theorie des Romans. Ein Geschichtes-philosophischer Versucht über die Formen der Grossen Epik. München: DTV, 1994.

. Heidelberger Philosophie der Kunst 1912-1914. Darmstadt; Neuwied:

Hermannn Luchterland, 1974.

. Sobre a essência e a forma do ensaio: Uma carta a Leo Popper. Revista UFG, ano X, n. 4, p. 104-121, jan./jun.2008.

MACHADO, Carlos Eduardo. As formas e a vida: estética e ética no jovem Lukács (1910-1918). São Paulo: Editora UNESP, 2004.

NOVALIS, Friedrich. Pólen. São Paulo: Iluminuras, 1988.

ROCHLITZ, Rainer. Le jeune Lukács. Théorie de la forme et philosophie de l'historie. Paris: Payot, 1983.

SCHILLER, F. Poesia Ingênua e sentimental. Tradução de Márcio Suzuki. São Paulo: Iluminuras, 1995, p. 44.

. Sobre a educação estética do homem. Tradução de Roberto Schwarz e Márcio Suzuki. São Paulo: Iluminuras, 2002.

Do Sublime ao Trágico. Tradução de Pedro Süssekind e Vladimir Vieira. Belo Horizonte: Autêntica Editora, 2011.

SILVA, Arlenice Almeida da. A autonomia da arte em Lukács. Revista UFG, ano X, n. 4, jan./jun. 2008.

O símbolo esvaziado: a teoria do romance do jovem György

Lukács. Trans/Form/Ação, Marília , v. 29, n. 1, p. 79-94, 2006. Disponível em:

$<$ http://www.scielo.br/scielo.php?script=sci_arttext\&pid=S0101-

31732006000100006\&lng=en\&nrm=iso >. Acesso em: 26 fev. 2016. 